\title{
Model Development and Experimental Validation of an Exhaust Brake Supported Dual Loop Exhaust Gas Recirculation on a Medium Duty Diesel Engine
}

\author{
Ádám NYERGES*, Máté ZÖLDY** \\ *Department of Automotive Technologies, Budapest University of Technology and Economics, 6 Stoczek St, building J, H- \\ 1111 Budapest, Hungary, Tel.: +36 1463 2380, E-mail: adam.nyerges@gjt.bme.hu (Corresponding Author) \\ **Department of Automotive Technologies, Budapest University of Technology and Economics, 6 Stoczek St, building J, \\ H-1111 Budapest, Hungary, E-mail: mate.zoldy@gjt.bme.hu
}

cross $^{\text {ref }}$ http://dx.doi.org/10.5755/j01.mech.26.6.25017

\section{Introduction}

The future of internal combustion engines is an important question of today's road transport. Alternative transmission systems gain space very slow therefore $\mathrm{CO}_{2}$ and harmful emissions of internal combustion engines have to be solved. These engines have many advantages for example the appropriate power and fuel consumption performance or their range. The emission regulations for the engines become more and more strict [1] and in the last few years many non-ideal operation zones got into focus for instance the cold operation on longer slopes.

In the development of Diesel engines which are almost dominated in commercial vehicles, the focus is on decreased $\mathrm{CO}_{2}$ emission, on lower particulate matter emission and lower $\mathrm{NO}_{\mathrm{x}}$ emission. The typical up-to-date solutions to reach these aims is the thermal management in the air path systems (for example in [2]) and the more and more complex exhaust gas after-treatment system where the temperatures are also controlled. Besides there are many researches to change the conventional Diesel fuel to an alternative one, typically to organic fuels for instance in [3 - 5]).

In a modern Diesel engine, the combustion process can be controlled in several ways. With exhaust gas recirculation systems and with several supporter valves the temperature and the composition of the intake flow can be controlled which have a strong effect on the quality of the combustion process (as it presented in [6] or in [7]). In this case the exhaust gas recirculation systems, the exhaust brakes and the intake throttles get new tasks in the air path system of the engine [8]. It is a complex task to decrease the amount of the $\mathrm{CO}_{2}$ and also the harmful components $\left(\mathrm{NO}_{\mathrm{x}}\right.$ and particulate matter emission) of the exhaust gas because basically it has contrary requirements for the combustion process: it "has to be paid" with higher fuel consumption for the lower emission [9-11]. Otherwise the formation of $\mathrm{NO}_{\mathrm{x}}$ and particulate matter emission is counterproductive as well. There are researches to realize alternative combustion processes to decrease most of the emissions altogether [12].

In this paper the aim is to make a simplified turbocharged engine model which can handle up-to-date elements in the air path system. The engine is a medium duty diesel engine i. e. the published engine model presents the challenges of the modelling of commercial vehicle engines which is not typical. The engine has a complex air path system with exhaust gas recirculation systems and exhaust brakes which is also not standard in this engine size [13].
The complexity gives big freedom of controlling the properties of the intake flow.

Engine air path models can be written to many gaseous states $[14,15]$ but basically there are two types of control oriented engine models: pressure-based models (for example in [16] and in [17]) and composition-based models (for example in [18] and in [19]). The developed engine model will be based on pressures in the pre-defined volumes and on the mass flow rates between these volumes. Due to the slimmer speed range of the commercial Diesel engines the model will have several simplifications compared to passenger Diesel engine models [20]. The research has much connection with previously published papers (for example [21]). Besides the published model has many solutions from [17] and [22].

\section{Exhaust gas recirculation systems}

With exhaust gas recirculation (EGR) $\mathrm{NO}_{\mathrm{x}}$ emission can be effectively decreased. $\mathrm{NO}_{\mathrm{x}}$ formation during the combustion process is mainly caused by the locally high flame temperature where the oxygen molecules dissociated and the active oxygen atoms can unseal the covalent bonds between the nitrogen molecules. Dou to the bigger heat capacity of the exhaust gas, the recirculated exhaust gas can decrease the local flame temperature in Diesel combustion processes [23, 24].

Basically there are two types of EGR systems: internal and external EGR systems. Internal exhaust gas recirculation can be realized by the timing of the intake and exhaust valve openings. The advantage of this solution is the fast response, however it is not possible to cool the recirculated exhaust gas. External exhaust gas recirculation requires additional pipes and valves in the air path system. Due to the longer loop the external exhaust gas recirculation has a slower response. On the other hand, it is easier to cool the recirculated exhaust gas. In this paper only the external exhaust gas recirculation will be discussed.

The available amount of the recirculated exhaust gas depended on several parameters. Basically it is determined by the air-fuel ratio of the combustion process: low air-flow ratio effects high particulate matter emission. Diesel engines work with lean combustion which is leaner on lower loads. The recirculated exhaust gas decreases the airfuel ratio of the combustion because it takes away the place from fresh intake air. On low loads the burnt gas fraction on the intake side can be high because the oxygen consumption 
of the engine is low.

In a first approach the engine is mounted with an EGR valve which can allow to feed back the exhaust gas to the intake side. In this layout the highest mass flow rate through the EGR system is determined by the pressure difference between the exhaust and the intake side. In many operation points this EGR rate is not enough for low $\mathrm{NO}_{\mathrm{x}}$ emission. The application of other valves in the air path system can increase the pressure difference i.e. EGR mass flow rate also can be increased. Intake throttles can reduce pressure in the intake side, exhaust brakes can increase pressure in the exhaust side. By these support valves high EGR rates (even more than 50\%) can be realized [21].

On a turbocharged engine the recirculated exhaust gas can be fed back on two ways. If the exhaust gas is fed back from upstream the turbine to downstream the compressor (typically downstream the intercooler) the system is called high pressure exhaust gas recirculation system (HP EGR). If the exhaust gas is fed back from downstream the turbine to upstream the compressor the system is called low pressure exhaust gas recirculation system (LP EGR). In this case supporting intake throttles or exhaust brakes also can be high or low pressure valves. Both systems have advantages and disadvantages as they can be seen in Table 1. The application of both systems on the same engine can achieve lower emission with almost unchanged performance [23].

Table 1

Comparison of HP and LP EGR [21]

\begin{tabular}{|l|l|}
\hline HP EGR & LP EGR \\
\hline $\begin{array}{l}\text { Fast response, favourable in } \\
\text { transient cycles }\end{array}$ & $\begin{array}{l}\text { Slower response, higher boost } \\
\text { pressure because all exhaust } \\
\text { gas goes through the turbine, } \\
\text { favourable in stationary cy- } \\
\text { cles. }\end{array}$ \\
\hline $\begin{array}{l}\text { The time for mixing the intake } \\
\text { air and the exhaust gas is } \\
\text { shorter }\end{array}$ & $\begin{array}{l}\text { Longer time for mixing, but } \\
\text { the condense water can dam- } \\
\text { age the compressor }\end{array}$ \\
\hline $\begin{array}{l}\text { It increases the fuel consump- } \\
\text { tion, but in high power de- } \\
\text { mand operation points it can } \\
\text { provide lower BSFC }\end{array}$ & $\begin{array}{l}\text { It increases the brake specific } \\
\text { fuel consumption less than the } \\
\text { HP EGR, because of the } \\
\text { higher boost pressure }\end{array}$ \\
\hline
\end{tabular}

Intake throttles and exhaust throttles have similar effects on the operation of the engine. Usually intake throttles are simpler and cheaper than the exhaust valves due to the lower operating temperature. Besides, high backpressure of the exhaust brakes can cause damage in the engine by opening the exhaust brakes.

In previous research the application of exhaust brakes provided lower effective fuel consumption [21]. From this reason in this paper the engine model will only have exhaust brakes. Exhaust brakes without exhaust gas recirculation can generate high backpressures when the flow is sonic through the valve. With open EGR valve this flow typically remains subsonic. An appropriate precise control of the EGR and the supporting valves can achieve lower emission and fuel consumption of the engine.

\section{Air path system description}

The modelled engine is a medium duty turbocharged Diesel engine. The technical data of it can be seen in Table 2. The air path system is completed with HP and LP EGR systems. Both of the EGR systems have coolers. The inlet of the LP EGR system is placed downstream the Diesel particulate filter and it also has a filter to protect the engine and the turbocharger from soot emission.

The engine has two exhaust brakes (EB). The first one is located downstream the turbine, it can increase the HP EGR mass flow rate. This exhaust brake would have a better operation downstream the HP EGR inlet (upstream the turbine) but due to space lack and the location requirements of the turbine it had to be located to the low pressure side. The second exhaust brake supports the LP EGR system therefore it is located downstream the LP EGR inlet.

In the air path system, the pressure and the temperatures can be measured upstream the compressor, in the intake manifold, in the exhaust manifold and downstream the turbine. The schematics of the air path system can be seen on Fig. 1.

Table 2

Parameters of the engine [13]

\begin{tabular}{|l|c|}
\hline Type & $\begin{array}{c}\text { Turbocharged diesel, in-line, 4 cyl- } \\
\text { inder }\end{array}$ \\
\hline Maximum power & $125 \mathrm{~kW}(25001 / \mathrm{min})$ \\
\hline Maximum torque & 3.91 \\
\hline Displacement & 1.176 \\
\hline Stroke/bore ratio & 17. márc \\
\hline Compression ratio & direct injection, common rail \\
\hline Injection system & 2.5 bar \\
\hline Maximum boost pressure &
\end{tabular}

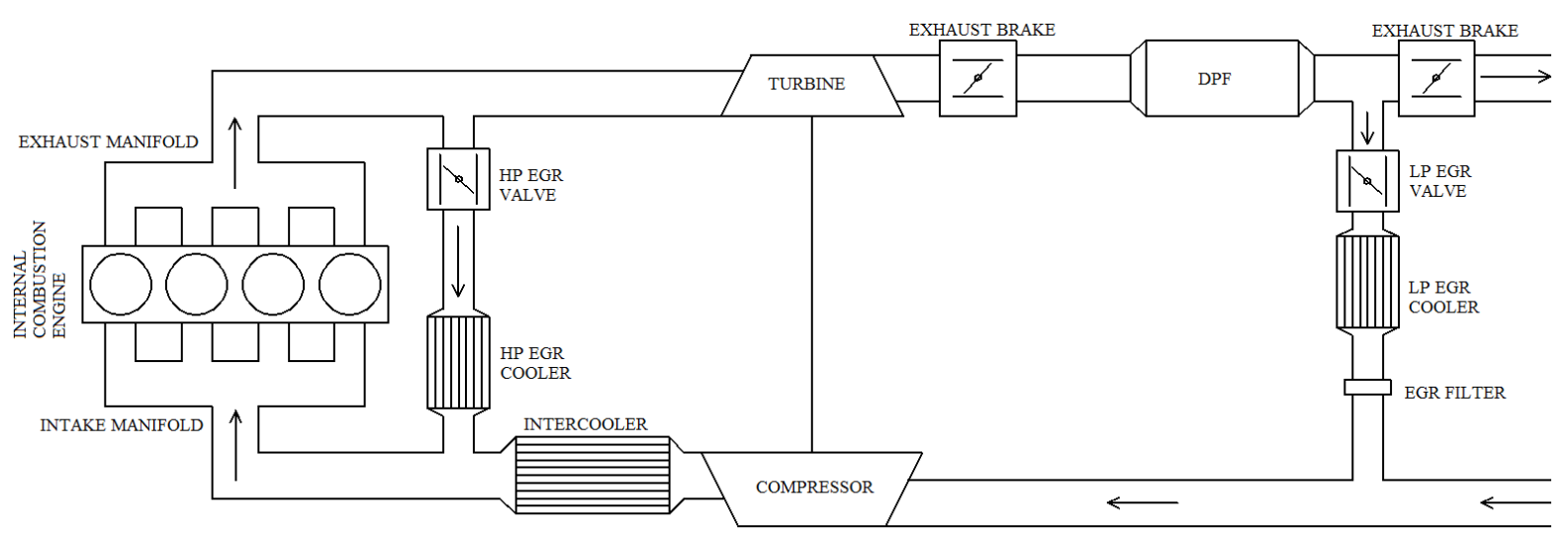

Fig. 1 Layout of the air path system 


\section{Engine system modelling}

\subsection{Modelling aims}

The goal of the modelling is to create the equations on the simplest form that give the same behaviour as the duel loop EGR system in the research engine. In this case the external performance (speed, torque, fuel consumption) of the engine is not a result of the model, it is an incoming signal. Control oriented models should have been simplified to a few state variables to reach fast numerical calculation speed and to able to use them in control theory [25].

The model development focuses on the air path system, the combustion process is less critical. The processes in the combustion chamber will be well simplified. In the model the combustion process increases the temperature of the gas flow to the exhaust manifold. The final model will be validated with the RMS error between the simulation and the engine dyno measurements. The aim is to achieve the RMS error below 10\% [25].

\subsection{Simplifications and basic equation laws}

The air path system will be divided to balance volumes wherein the pressures, the temperatures and the compositions of the fluids can be estimated equals. In a pressurebased air path system model the differential equations are based on the mass conservation and the energy conservation laws. The place dependence of the variables will be neglected i.e. the momentum conservation law will also be ignored. Pressures in each volume can change in two ways: by the difference between the incoming and the leaving mass flow rates and by heat transfer. If the temperature of the incoming mass flow rate is different from the temperature inside, the change can be handled as a mass flow rate into the volume (without temperature differences) and an additional external heat transfer $[17,26]$. Besides to have a simpler model it is expedient to neglect as many temperature changes as many possible under the validation criteria.

The inertia of the turbocharger has a significant effect on the operation of the engine and on the operation of the EGR systems. The mechanical balance of the turbocharger will also have a state variable to get the dynamics of it. The differential equation will be written to the compressor power [17].
Summarizing the presented aims the simplifications and requirements for the model:

- the engine model should be described with differentialalgebraic equations, with ordinary differential equations (OD model);

- fluids can be modelled as ideal gases; this is the simplest way;

- gases modelled as air in the whole system i.e. the changes of the adiabatic gas constant, the specific gas constant and the specific heat is neglected;

- state variables should be only pressures and the compressor power, the dynamics of the temperature changes are ignored;

- $\quad$ if it is possible temperatures modelled as constants or temperature changes are neglected between the balance volumes;

- temperature is equal in each balance volumes, the mixing of different gases come off endless fast. The temperature of the outflowing gases from the balance volumes are the balance volume's temperature;

- heat transfer through the walls is neglected in the whole system;

- potential energy is neglected;

- exhaust gas recirculation does not affect the combustion process (from the aspect of pressures and temperatures);

- fuel mass flow rate is neglected due to its small amount compared to the gas mass flow rates in the air path system;

- efficiencies that typically have several dependencies in reality should applied as a constant or on the achievable simplest way.

\subsection{Applied balance volumes and input signals of the model}

The air path of the engine is divided into six different places where the pressure and the temperature can be changed. These six balance volumes are (Fig. 2):

- $\quad$ ambient environment on the intake (marked with 0) and on the exhaust side (marked with 6);

- volume downstream the compressor where LP EGR is fed back (marked with 1);

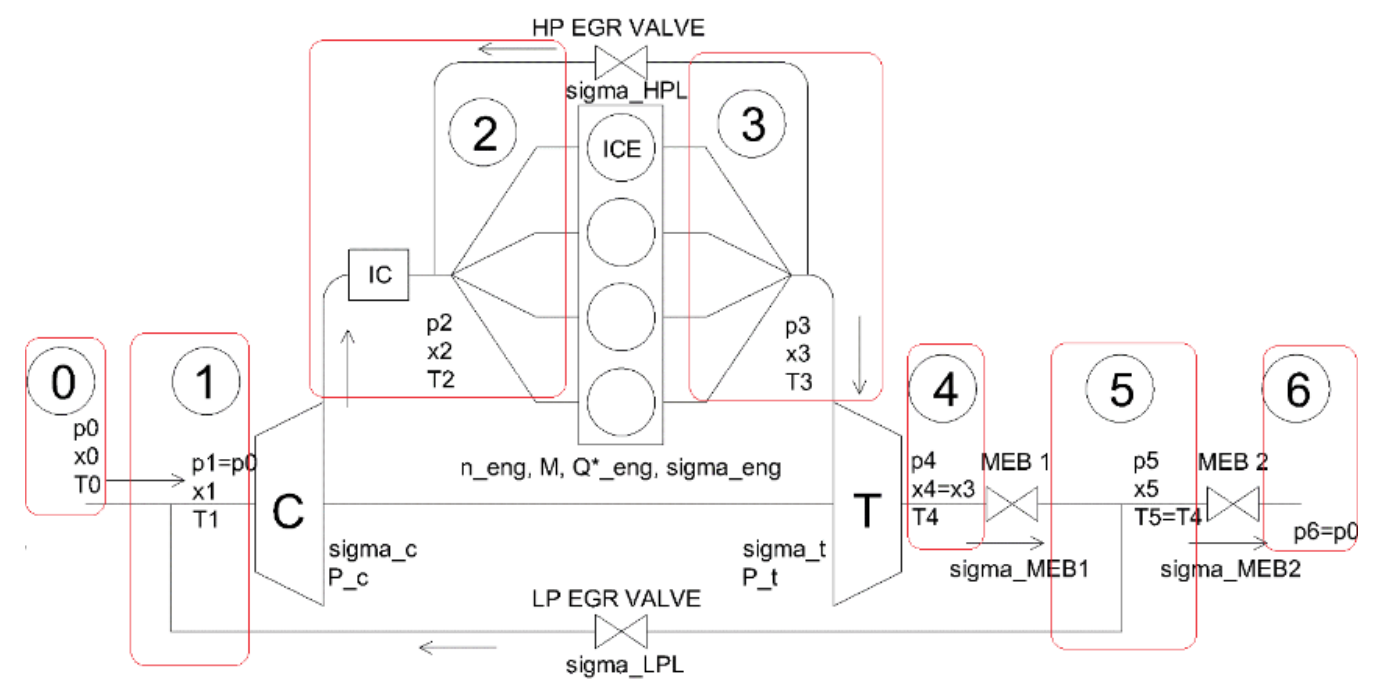

Fig. 2 The layout of the divided air path system [21] 
- volume between the compressor and the engine i.e. the intake manifold of the engine (marked with 2). HP EGR is fed back here;

- $\quad$ volume between the engine and the turbine i.e. the exhaust manifold (marked with 3 );

- $\quad$ volume between the turbine and the first exhaust brake (marked with 4);

- $\quad$ volume between the exhaust brakes (marked with 5).

The model has the following inputs:

- $\quad$ engine speed;

- fuel mass flow rate;

- $\quad$ HP EGR valve effective area;

- $\quad$ LP EGR valve effective area;

- first exhaust brake effective area;

- $\quad$ second exhaust brake effective area.

During the model development process several requirements and parameters have been changed. Typically, the temperatures on the exhaust side were calculated more precisely. Besides the efficiencies were also estimated on a more complex way. In the next paragraphs the finally achieved simplified version of the engine model will be presented.

\subsection{Equations of the balance volumes}

\subsubsection{Intake manifold pressure}

The intake manifold has inlets from the compressor and the HP EGR pipe. It has an outlet to the intake valves of the internal combustion engine. Temperature changes are negligible here i.e. the differential equation is based only the mass conservation law, it is given as it follows:

$$
\frac{d p_{2}}{d t}=\frac{R T_{2}}{V_{2}}\left(\sigma_{c}-\sigma_{e n g}+\sigma_{H P L}\right)
$$

\subsubsection{Exhaust manifold pressure}

There are several methods to estimate the impact of heat release on pressures and temperatures in the exhaust system. The following method will be based on [13]. The temperature in the exhaust manifold is significantly higher than in the intake side i.e. it is not negligible. Due to the high temperature the heat transfer through the walls is not negligible. The exhaust manifold has an inlet from the exhaust valves (from the engine cylinder) and it has an outlet to the turbine and the HP EGR system. With the mass and the energy conservation law the differential equation is given as it follows:

$$
\frac{d p_{3}}{d t}=\frac{\kappa R}{V_{3}}\left[\sigma_{\text {eng }} T_{3}-\sigma_{t} T_{3}-\sigma_{H P L} T_{3}-\frac{\dot{Q}_{3 h l}(\kappa-1)}{\kappa R}\right]
$$
lows:

The engine outlet enthalpy can be written as it fol-

$$
\dot{H}_{e o}=\frac{\kappa R}{\kappa-1} \sigma_{\text {eng }} T_{\text {eng }} .
$$

By Eq. (3), Eq. (2) can be modified to the following

$$
\frac{d p_{3}}{d t}=\frac{\kappa R}{V_{3}}\left[\left(\dot{H}_{e o}-\dot{Q}_{3 h l}\right) \frac{\kappa-1}{\kappa R}-\sigma_{t} T_{3}-\sigma_{H P L} T_{3}\right] .
$$

The signed sum of the engine outlet enthalpy and the heat loss gives the heat transfer which heats the flow in the third balance volume compared to the second balance volume. This enthalpy should be equal with the sum of the engine intake enthalpy and a part of the heat release in the cylinder.

$$
\dot{H}_{e o}-\dot{Q}_{3 h l}=\dot{H}_{e i}+\dot{Q}_{e n g} .
$$

According to equation (5), equation (4) can be written as:

$$
\frac{d p_{3}}{d t}=\frac{\kappa R}{V_{3}}\left[\left(\dot{H}_{e i}+\dot{Q}_{e n g}\right) \frac{\kappa-1}{\kappa R}-\sigma_{t} T_{3}-\sigma_{H P L} T_{3}\right] .
$$

Engine intake enthalpy is known:

$$
\dot{H}_{e i}=\frac{\kappa R}{\kappa-1} \sigma_{e n g} T_{2}
$$

Finally, the exhaust gas fraction of the heat release also can be written with equation (8). $\eta_{\text {egf }}$ is the parameter which can tune the model. The fuel mass flow rate is given from the EDC (Electronic Diesel Control).

$$
\dot{Q}_{\text {eng }}=\sigma_{f} H_{l} \eta_{\text {egf }} .
$$

By the previous equations the final form of the differential equation of the exhaust manifold can be written:

$$
\frac{d p_{3}}{d t}=\frac{\kappa R}{V_{3}}\left[\sigma_{\text {eng }} T_{2}-\sigma_{t} T_{3}-\sigma_{H P L} T_{3}+\frac{\dot{Q}_{\text {eng }}(\kappa-1)}{\kappa R}\right] .
$$

\subsubsection{Exhaust system pressure downstream the turbine}

The balance volume downstream the turbine has an inlet from the turbine and it has an outlet to the first exhaust brake. Temperature changes are also negligible here i.e. the differential equation can be written:

$$
\frac{d p_{4}}{d t}=\frac{R T_{4}}{V_{4}}\left(\sigma_{t}-\sigma_{E B 1}\right)
$$

\subsubsection{Exhaust system pressure downstream the first exhaust brake}

The exhaust system between the exhaust brakes has an inlet from the first exhaust brake and it has outlets to the second exhaust brake and the LP EGR system. The differential equation is given as it follows:

$$
\frac{d p_{5}}{d t}=\frac{R T_{5}}{V_{5}}\left(\sigma_{E B 1}-\sigma_{E B 2}-\sigma_{L P L}\right) .
$$




\subsubsection{Compressor power}

The last state variable is the compressor power. The exhaust gas enthalpy turns into mechanical energy of the turbocharger shaft. $\tau_{t c}$ takes into consideration the inertia of the shaft. Finally, the mechanical energy turns into compressor power where $\eta_{m_{-} t c}$ takes into account the mechanical efficiency of the turbocharger.

$$
\frac{d P_{c}}{d t}=\frac{1}{\tau_{\mathrm{tc}}}\left(-P_{c}+\eta_{m_{-} t c} P_{t}\right),
$$

where: $\eta_{m_{-} t c}$ is modelled with a turbine power depended on a characteristic curve. $\eta_{m_{-} t c}$ as a constant did not allowed accurate results both on low and high loads. The final curve can be seen in Fig 3 .

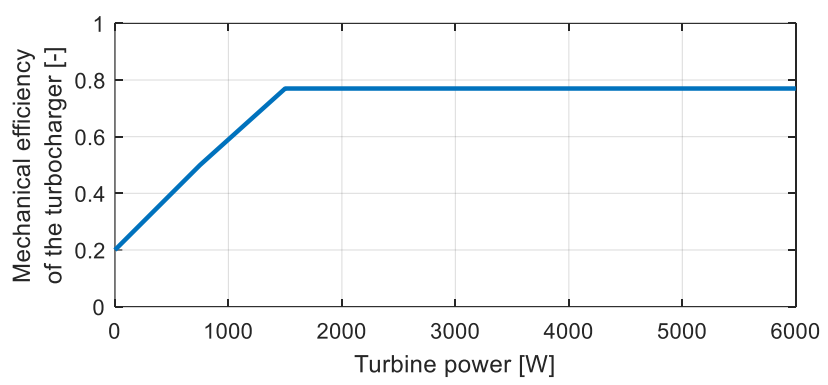

Fig. 3 The applied characteristics of the mechanical efficiency of the turbocharger

\subsection{Additional equations}

\subsubsection{Internal combustion engine}

The internal combustion engine generates the flows in the air path system. In the reality it is a periodic flow with significant pressure waves. In concentrated parameter models the pressure waves are neglected (the impulse conservation law is not used). In a four stroke engine by the engine speed and by the displacement the mass flow rate through the engine can be estimated as it follows:

$$
\sigma_{\text {eng }}=\eta_{v o l} \frac{p_{2}}{R T_{2}} \frac{V_{d} n_{\text {eng }}}{2}
$$

In Eq. (13) the volumetric efficiency of the engine is modelled as a constant - in medium and high duty Diesel engines with small speed range the change of the volumetric efficiency can be small. One of the main impacts of the combustion process in the air path system is the high gas temperature in the exhaust manifold. As in (5), the temperature increase also can be estimated by the intake enthalpy and by the heat release from the combustion process [22]:

$$
T_{3}=\frac{c_{p} \sigma_{e n g} T_{2}+\sigma_{f} H_{l} \eta_{e g f}}{c_{p} \sigma_{e n g}},
$$

where: $\eta_{\text {egf }}$ is depended on several engine parameters for instance the indicated efficiency of the engine or the heat transfer through the walls of the cylinders. It can be estimated with a look-up table. The surface of $\eta_{e g f}$ can be seen in Fig. 4. $\eta_{e g f}$ is depended more on the fuel mass flow rate, but, according to the validation experiences, the engine speed dependence is not negligible on low loads.

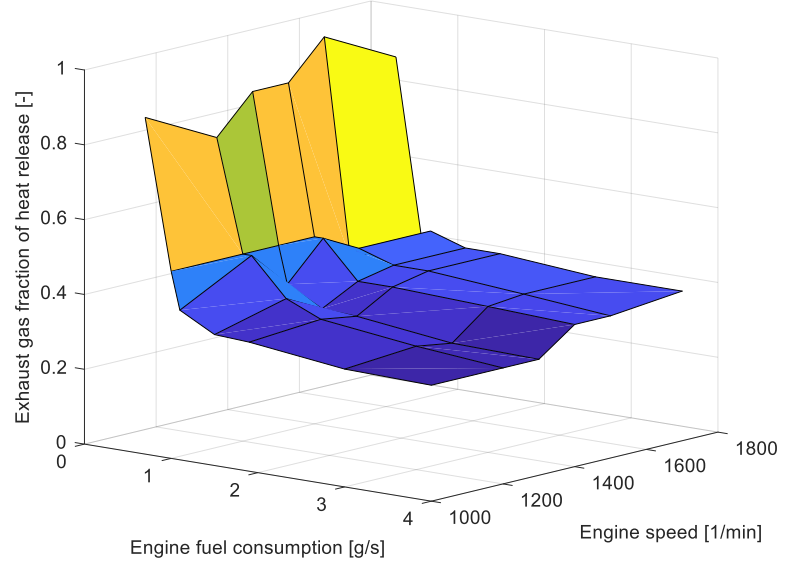

Fig. 4 The applied characteristics of the exhaust gas fraction of heat release

\subsubsection{Turbocharger equations}

The equations of the turbocharger give the connection between the mass flow rate, the power and the temperature. They can be estimated with the equations from [27].

The mass flow rate of the turbine is modelled with an experimental equation where $c_{t}$ and $k_{t}$ are the parameters which can tune the characteristics of the turbine:

$$
\sigma_{t}=\frac{p_{3}}{\sqrt{T_{3}}} c_{t} \sqrt{1-\left(\frac{p_{3}}{p_{4}}\right)^{k_{t}}}
$$

With the turbine mass flow rate, the exhaust manifold temperature and the pressure ratio on the turbine, the turbine power can be estimated:

$$
P_{t}=\eta_{t} T_{3} \frac{\kappa R}{\kappa-1}\left[1-\left(\frac{p_{3}}{p_{4}}\right)^{\frac{\kappa-1}{\kappa}}\right] \sigma_{t}
$$

The turbine power from (16) gives the compressor power by (12). By the compressor power the compressor mass flow rate can be estimated by (17).

$$
\sigma_{c}=\frac{\eta_{c}}{\frac{R \kappa}{\kappa-1} T_{1}} \frac{P_{c}}{\left(\frac{p_{2}}{p_{1}}\right)^{\frac{\kappa-1}{\kappa}}-1}
$$

Both the turbine and the compressor isentropic efficiencies are modelled with constants.

\subsubsection{Orifice equations}

Mass flow rates between two volumes are estimated by the orifice equations. Taken in consideration the pressure differences and the effective areas of the valves, none of the flows is sonic in the normal operation range (the exhaust brakes should always work with open EGR valves).

The HP EGR mass flow rate can be estimated as it follows: 


$$
\sigma_{H P L}=A_{H P L} \frac{p_{3}}{\sqrt{R T_{3}}} \sqrt{\frac{2 p_{2}}{p_{3}}\left(1-\frac{p_{2}}{p_{3}}\right)} .
$$

The pressure in the LP EGR system is always higher on the exhaust side due to the backpressure of the exhaust system. The orifice equation to the LP EGR system can be written to the following form:

$$
\sigma_{L P L}=A_{L P L} \frac{p_{5}}{\sqrt{R T_{5}}} \sqrt{\frac{2 p_{1}}{p_{5}}\left(1-\frac{p_{1}}{p_{5}}\right)} .
$$

The mass flow rate of the first exhaust brake can be estimated with the following equation:

$$
\sigma_{E B 1}=A_{E B 1} \frac{p_{4}}{\sqrt{R T_{4}}} \sqrt{\frac{2 p_{5}}{p_{4}}\left(1-\frac{p_{5}}{p_{4}}\right)} .
$$

And finally the mass flow rate of the second exhaust brake can be estimated as it follows:

$$
\sigma_{E B 2}=A_{E B 2} \frac{p_{5}}{\sqrt{R T_{5}}} \sqrt{\frac{2 p_{0}}{p_{5}}\left(1-\frac{p_{0}}{p_{5}}\right)} .
$$

\subsubsection{Pressures and temperatures}

The pressure and temperature changes in many neighbouring volumes are important to reach the goal of the paper to get a significantly simplified model.

The pressure in the first balance volume is ambient, but in the sixth balance volume it has to be higher due to the backpressure of the exhaust system.

$$
p_{1} \approx p_{0}
$$

$$
\left[\begin{array}{c}
p_{2} \\
p_{3} \\
p_{4} \\
p_{5} \\
P_{c}
\end{array}\right]=\left[\begin{array}{c}
f_{1}(\mathbf{x}, \mathbf{d}) \\
f_{2}(\mathbf{x}, \mathbf{d}) \\
f_{3}(\mathbf{x}, \mathbf{d}) \\
0 \\
f_{5}(\mathbf{x}, \mathbf{d})
\end{array}\right]+\left[\begin{array}{cccc}
g_{11}(\mathbf{x}, \mathbf{d}) & 0 & 0 & 0 \\
g_{21}(\mathbf{x}, \mathbf{d}) & 0 & 0 & 0 \\
0 & g_{32}(\mathbf{x}, \mathbf{d}) & 0 & 0 \\
0 & g_{42}(\mathbf{x}, \mathbf{d}) & g_{43}(\mathbf{x}, \mathbf{d}) & g_{44}(\mathbf{x}, \mathbf{d}) \\
0 & 0 & 0 & 0
\end{array}\right]\left[\begin{array}{c}
A_{H P} \\
A_{E B 1} \\
A_{L P} \\
A_{E B 2}
\end{array}\right] .
$$

where: $\mathbf{x}(\mathbf{t})$ means the state vector which contains the intake manifold pressure, the exhaust manifold pressure, the pressure downstream the turbine, the pressure downstream the first exhaust brake and the compressor power. $\mathbf{u}(\mathbf{t})$ vector contains the control inputs: the effective area of the HP EGR valve and its supporter exhaust brake, and also the effective area of the LP EGR valve and its supporter exhaust brake. $\mathbf{d}(\mathbf{t})$ vector contains the disturbances on the model, the engine speed and the fuel mass flow rate:

$$
\begin{aligned}
& \mathbf{x}(\mathbf{t})=\left[\begin{array}{lllll}
p_{2} & p_{3} & p_{4} & p_{5} & P_{c}
\end{array}\right]^{T}, \\
& \mathbf{u}(\mathbf{t})=\left[\begin{array}{llll}
A_{H P} & A_{E B 1} & A_{L P} & A_{E B 2}
\end{array}\right]^{T}, \\
& \mathbf{d}(\mathbf{t})=\left[\begin{array}{ll}
n_{\text {eng }} & \sigma_{f}
\end{array}\right]^{T} .
\end{aligned}
$$

Putting the whole system into one matrix equation: 


$$
g_{21}(\mathbf{x}, \mathbf{d})=-p_{3} \frac{\kappa \sqrt{R}}{V_{3}} \sqrt{\frac{c_{p} \eta_{v o l} \frac{p_{2}}{R} \frac{V_{d} n_{\text {eng }}}{2}+\sigma_{f} H_{l} \eta_{\text {egf }}}{c_{p} \eta_{v o l} \frac{p_{2}}{R T_{0}} \frac{V_{d} n_{\text {eng }}}{2}}} \sqrt{\frac{2 p_{2}}{p_{3}}\left(1-\frac{p_{2}}{p_{3}}\right)} .
$$

The elements of the third state equation are:

$$
\begin{gathered}
f_{3}(\mathbf{x}, \mathbf{d})=p_{3} \frac{R}{V_{4}} \sqrt{\frac{c_{p} \eta_{v o l} \frac{p_{2}}{R_{2}} \frac{V_{d} n_{\text {eng }}}{2}+\sigma_{f} H_{l} \eta_{\text {egf }}}{c_{p} \eta_{v o l} \frac{p_{2}}{R T_{0}} \frac{V_{d} n_{\text {eng }}}{2}}\left[1-\eta_{t}\left(1-\left(\frac{p_{3}}{p_{4}}\right)^{\frac{1-\kappa}{\kappa}}\right] \cdot c_{t} \sqrt{1-\left(\frac{p_{3}}{p_{4}}\right)^{k_{t}}},\right.} \\
g_{32}(\mathbf{x}, \mathbf{d})=-p_{4} \frac{\sqrt{R}}{V_{4}} \sqrt{\frac{c_{p} \eta_{v o l} \frac{p_{2}}{R} \frac{V_{d} n_{\text {eng }}}{2}+\sigma_{f} H_{l} \eta_{\text {egf }}}{c_{p} \eta_{v o l} \frac{p_{2}}{R T_{0}} \frac{V_{d} n_{\text {eng }}}{2}}} \sqrt{\frac{2 p_{5}}{p_{4}}\left(1-\frac{p_{5}}{p_{4}}\right)}
\end{gathered}
$$

The elements of the fourth state equation are:

$$
\begin{aligned}
& g_{42}(\mathbf{x}, \mathbf{d})=p_{4} \frac{\sqrt{R}}{V_{5}} \sqrt{\frac{c_{p} \eta_{v o l} \frac{p_{2}}{R} \frac{V_{d} n_{\text {eng }}}{2}+\sigma_{f} H_{l} \eta_{\text {egf }}}{c_{p} \eta_{v o l} \frac{p_{2}}{R T_{0}} \frac{V_{d} n_{\text {eng }}}{2}}} \sqrt{\frac{2 p_{5}}{p_{4}}\left(1-\frac{p_{5}}{p_{4}}\right)}, \\
& g_{43}(\mathbf{x}, \mathbf{d})=-p_{5} \frac{\sqrt{R}}{V_{5}} \sqrt{\frac{c_{p} \eta_{v o l} \frac{p_{2}}{R} \frac{V_{d} n_{\text {eng }}}{2}+\sigma_{f} H_{l} \eta_{\text {egf }}}{c_{p} \eta_{v o l} \frac{p_{2}}{R T_{0}} \frac{V_{d} n_{\text {eng }}}{2}}} \sqrt{\frac{2 p_{0}}{p_{5}}\left(1-\frac{p_{0}}{p_{5}}\right)}, \\
& g_{44}(\mathbf{x}, \mathbf{d})=-p_{5} \frac{\sqrt{R}}{V_{5}} \sqrt{\frac{c_{p} \eta_{v o l} \frac{p_{2}}{R} \frac{V_{d} n_{\text {eng }}}{2}+\sigma_{f} H_{l} \eta_{\text {egf }}}{c_{p} \eta_{v o l} \frac{p_{2}}{R T_{0}} \frac{V_{d} n_{\text {eng }}}{2}}} \sqrt{\frac{2 p_{0}}{p_{5}}\left(1-\frac{p_{0}}{p_{5}}\right)} .
\end{aligned}
$$

The elements of the fifth state equation are:

$$
f_{5}(\mathbf{x}, \mathbf{d})=p_{3} \frac{\eta_{m_{-} t c} \eta_{t}}{\tau_{t c}} \sqrt{\frac{c_{p} \eta_{v o l} \frac{p_{2}}{R} \frac{V_{d} n_{\text {eng }}}{2}+\sigma_{f} H_{l} \eta_{\text {egf }}}{c_{p} \eta_{v o l} \frac{p_{2}}{R T_{0}} \frac{V_{d} n_{\text {eng }}}{2}}} \frac{\kappa R}{\kappa-1}\left[1-\left(\frac{p_{3}}{p_{4}}\right)^{\frac{\kappa-1}{\kappa}}\right] c \sqrt{1-\left(\frac{p_{3}}{p_{4}}\right)^{k_{t}}}-\frac{1}{\tau_{t c}} P_{c} .
$$

\section{Model validation}

The long term goal of the research is emission control by EGR systems. Regulations prescribe the emission of internal combustion engines. Therefore, the model performance was evaluated in EU legally mandated World Harmonized Transient Cycle [1].

\subsection{Measurements and steps of validation}

The validation of the model was made in two steps. At the first step most of the model parameters were adjusted on stationary operation points. On the second step the other parameters were set with transient cycles.

At the first phase of the validation the engine works without EGR. With stationary operation points the following parameters of the turbocharger can be set:
- $\quad$ compressor isentropic efficiency;

- $\quad$ turbine isentropic efficiency;

- $\quad$ turbine model parameters;

- $\quad$ mechanical efficiency of the turbocharger.

Apart from the turbocharger, the engine's volumetric efficiency and the exhaust gas fraction of the released heat also can be set. For the validation in transient cycles a representative part of WHTC was chosen. From 1190 to 1370 s several different operation points can be found: idle, high load on low revs and low loads on higher revs with slow and fast changes too. In the validation process negative loads were not used because the applied eddy current brake cannot produce negative torques. The selected period is depicted in Fig. 5. The engine speed and the fuel consumption signal is given from the engine's ECU by CAN messages. The torque signal is given from a tension load cell (Acell TC 30kg 462892). 
During the measurements the position of the EGR valves does not change because the aim was to set pressure drop of the EGR systems. Besides, on higher loads with EGR the engine can reach its air-fuel ratio limit. To avoid very low air-fuel ratios the WHTC torque demand was modified to the $75 \%$ and to the $50 \%$ compared to the original torque demand. With closed EGR valves $75 \%$ was the torque demand multiplier, with opened ones $50 \%$ was the multiplier. The position of the exhaust brakes is also not changed because the first aim is to set the backpressure of the exhaust system. can be set:

By the transient cycles the following parameters

- $\quad$ volumes of the balance volumes; effective areas of the valves and exhaust brakes;

time constant of the turbocharger.

Finally, the validation can be continued with open EGR valves. In these operation cycles the effective areas of the valves can be set.

A key part of the validation is the setting of the exhaust system backpressure and the setting of the model parameters of the turbine. These parameters determine the pressure ratio on the turbine which gives the turbine power. From the turbine power the compressor power can be estimated with (12) which also a key step for estimating the boost pressure in the intake manifold. Basically this energy transformation chain determines the excellent behaviour of the model.
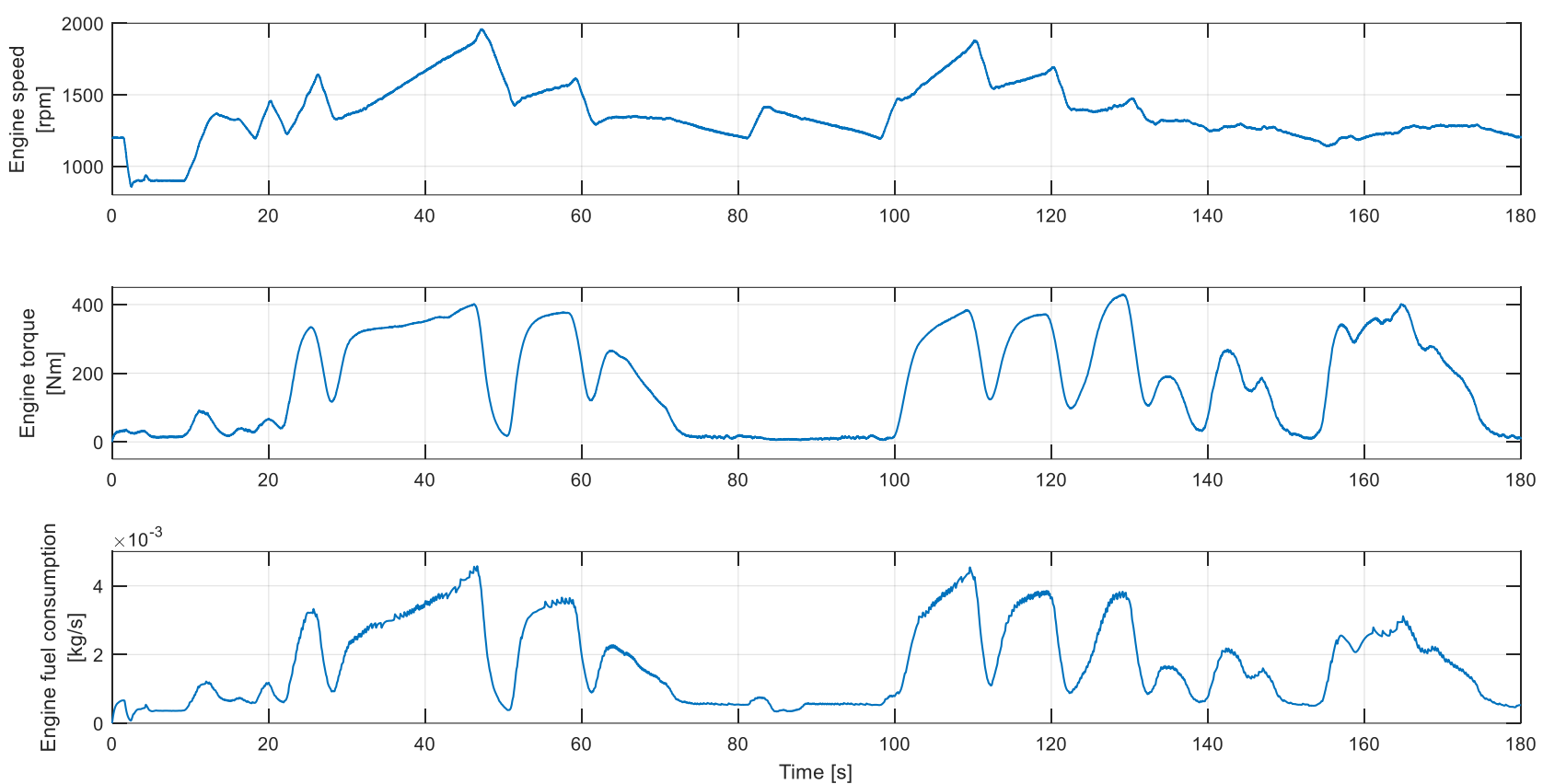

Fig. 5 The applied input signals for the model from WHTC

\subsection{Evaluation of validation}

The validation can be done for those state variables which can be measured:

- $\quad$ intake manifold pressure $\left(p_{2}\right)$;

- $\quad$ exhaust manifold pressure $\left(p_{3}\right)$;

- $\quad$ pressure between the turbine and the first exhaust brake $\left(p_{4}\right)$.

Pressure measuring is done with Delta OHM HD9408T barometric pressure sensors. The accuracy of the sensor is $\pm 0.5 \mathrm{mbar}$. The pressure changes in the air path system are in $0.1 \mathrm{~s}$ order of magnitude, the used pressure sensor is appropriate.

In a control oriented model, no more validation parameters needed, because the behaviour of the inner variables is not important from the aspect of model operation.

The measured and the simulated results were compared with each other with their RMS error:

$$
\varepsilon=\sqrt{\frac{1}{T} \int_{0}^{T}\left(\frac{p_{\text {meas }}-p_{\text {sim }}}{p_{\text {meas }}}\right)^{2} d t .}
$$

In Fig. 6 the measured and the simulated pressures can be compared with each other with closed EGR valves.
As it can be seen the simulated pressure follows well the measured pressure on medium and high loads. On low loads the simulation sometimes has faster dynamics compared to the measurement. To get the acceptable accuracy it was important to set well the backpressure of the exhaust system which determines the pressure downstream the turbine. Finally, (also with well-set turbine parameters) the exhaust and the intake manifold pressure also follow well the measurements. Due to the simplifications a compromise was necessary where every simulated pressure follows with acceptable accuracy the measured signals. Each simulated pressure signals could be more accurate, but the presented results perform the expected accuracy with every simulated signal.

In Fig. 7 the measured and the simulated pressure can be seen with open HP EGR valve. HP EGR changes the operation of the turbocharger because the recirculated exhaust gas decreases the mass flow rate through the turbine and also through the compressor. Because of these the boost pressure and the backpressure of the turbine also decreases. The amount of the HP EGR mass flow rate depends on the pressure difference between the exhaust and the intake manifold. This pressure difference depends on the cooperation between the engine and the turbocharger. Therefore, the HP EGR mass flow rate determines the pressures in the air path system. 

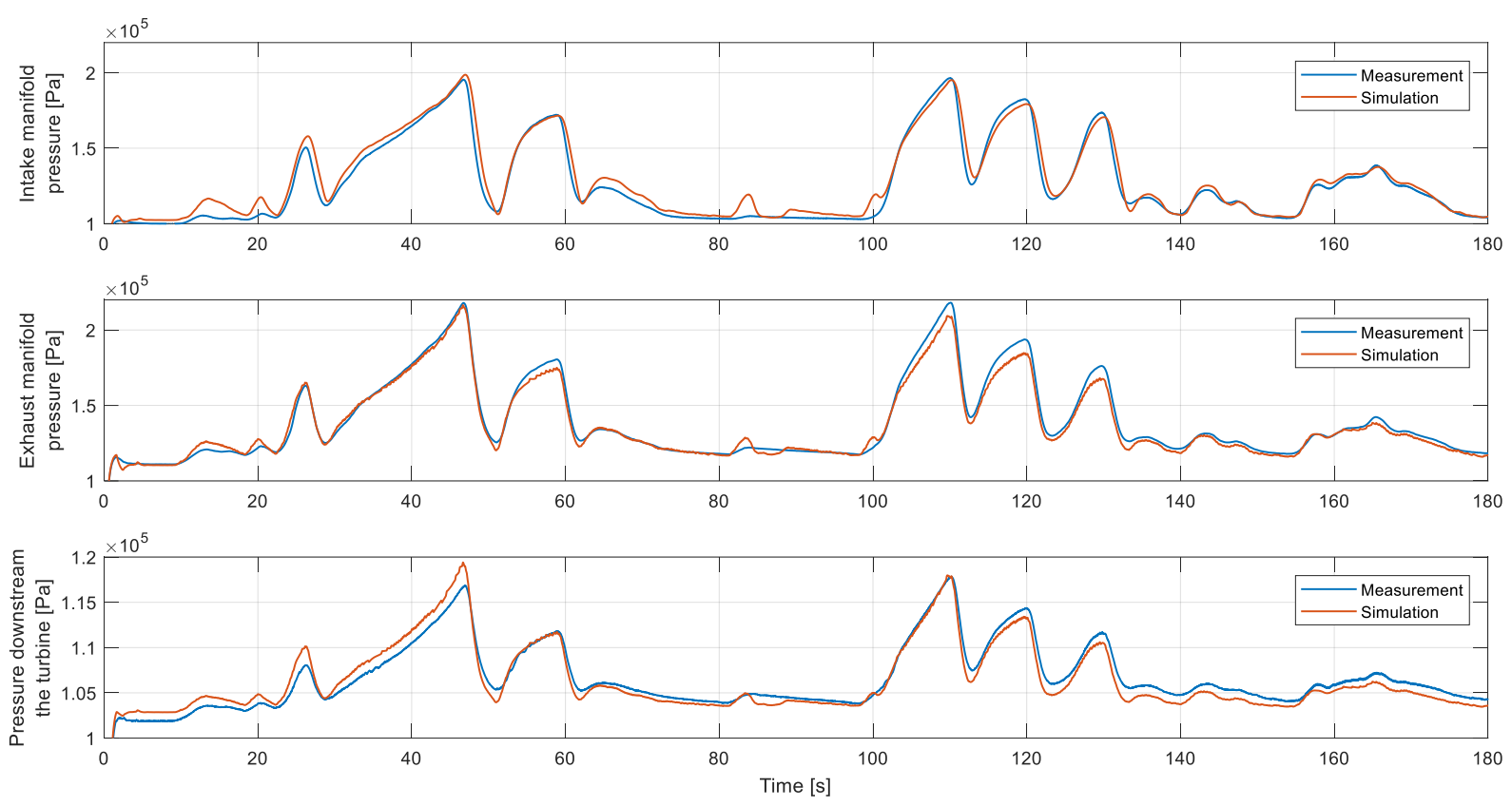

Fig. 6 Measured and simulated pressures without EGR (75\% WHTC engine torque demand)
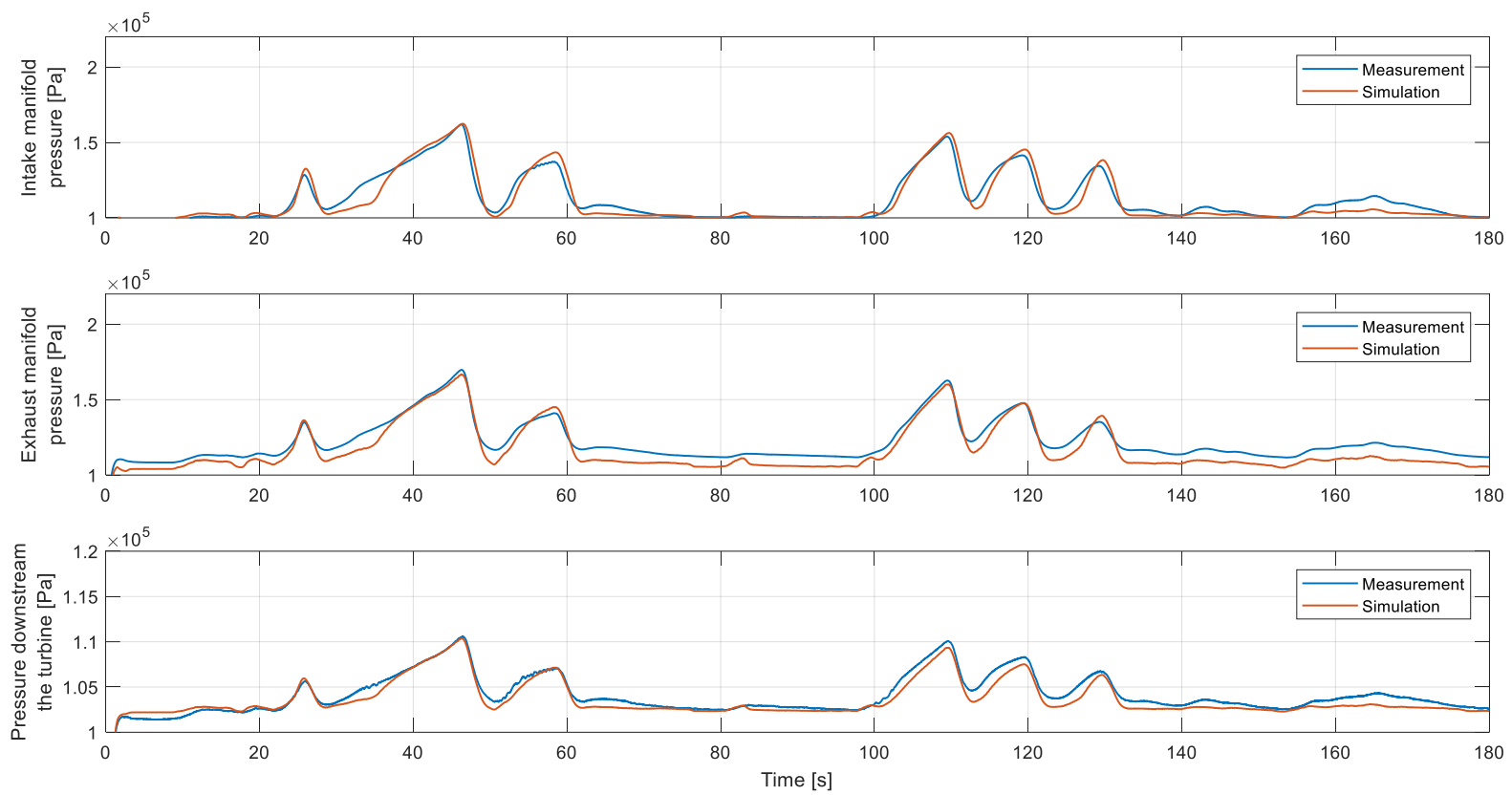

Fig. 7 Measured and simulated pressures with HP EGR (50\% WHTC engine torque demand)

With LP EGR the operation of the internal combustion engine does not change on lower loads because the mass flow rate through the turbocharger does not change. Therefore, the main step of the validation is to set the effective area of the LP EGR valve. If the simulated pressure downstream the turbine follows well the measurement, the intake and the exhaust manifold pressure will also follow well it. Because of this, only the pressure downstream the turbine is depicted in Fig. 8. The LP EGR mass flow rate is determined by the pressure ratio between the exhaust system and the low pressure part of the intake side. Therefore, the accuracy of the pressure in the exhaust system is important: the relative pressures are small here i.e. the pressure ratio is sensitive to the accuracy.

In Table 3 the RMS errors can be seen for all operation modes. A typical aim for control oriented models is to achieve the error below 10\% [25]. As it can be seen all of the RMS errors are below $6 \%$ i.e. the model development has reached its goal. The parameters that are used in the simulation model are listed in Table 4.

Table 3

RMS errors between the measured and the simulated pressures

\begin{tabular}{|c|c|c|c|}
\hline Validation mode & Intake manifold pressure & Exhaust manifold pressure & Pressure downstream the turbine \\
\hline Operation without EGR & $4.43 \%$ & $2.76 \%$ & $1.16 \%$ \\
\hline Operation with HP EGR & $3.82 \%$ & $5.33 \%$ & $0.77 \%$ \\
\hline Operation with LP EGR & $5.18 \%$ & $3.07 \%$ & $0.97 \%$ \\
\hline
\end{tabular}




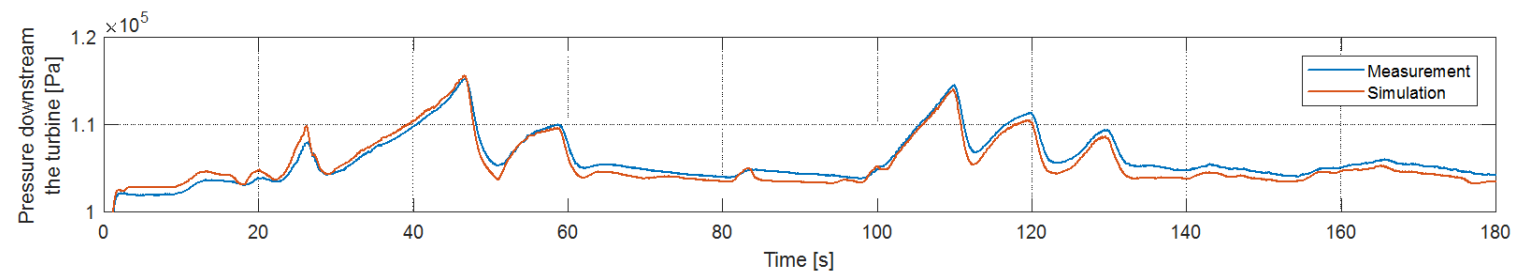

Fig. 8 Measured and simulated pressure downstream the turbine with LP EGR (50\% engine torque in WHTC)

Table $4 \quad$ References

List of applied model parameters

\begin{tabular}{|l|l|l|}
\hline $\begin{array}{l}\text { Sym } \\
\text { bol }\end{array}$ & Parameter name & Value \\
\hline$A_{H P L}$ & Area of the HP EGR valve, $\mathrm{m}^{2}$ & 0.0002405 \\
\hline$A_{L P L}$ & Area of the LP EGR valve, $\mathrm{m}^{2}$ & 0.0003926 \\
\hline$A_{E B 1}$ & Area of the first exhaust brake, $\mathrm{m}^{2}$ & 0.005027 \\
\hline$A_{E B 2}$ & Area of the second exhaust brake, $\mathrm{m}^{2}$ & 0.005027 \\
\hline$c_{t}$ & Turbine mass flow model parameter 1 & 0.0000232 \\
\hline$\eta_{e g f}$ & Exhaust gas fraction of the released heat & see Fig 4 \\
\hline$\eta_{v o l}$ & Volumetric efficiency of the engine, - & 0.9 \\
\hline$H_{l}$ & Diesel lower heating value, J/kg & 43250000 \\
\hline$k_{t}$ & Turbine model parameter & -1.47 \\
\hline$\kappa$ & Adiabatic exponent of air & 1.4 \\
\hline$\eta_{m_{t} t c}$ & Mechanical efficiency of the turbocharger & see Fig 3 \\
\hline$p_{0}$ & Ambient pressure, Pa & 100000 \\
\hline$\Delta p_{e s}$ & Relative backpres. of the exhaust system, $\mathrm{Pa}$ & 3000 \\
\hline$R$ & Specific gas constant of air, $\mathrm{J} / \mathrm{kgK}$ & 287 \\
\hline$T_{0}$ & Ambient temperature, $\mathrm{K}$ & 300 \\
\hline$\Delta T_{i c}$ & Temp. increase through the compressor, $\mathrm{K}$ & 20 \\
\hline$\tau_{t c}$ & Time constant of turbocharger, $\mathrm{s}$ & 0.2 \\
\hline$V_{2}$ & Volume of the intake manifold, $\mathrm{m}^{3}$ & 0.085 \\
\hline$V_{3}$ & Volume of the exhaust manifold, $\mathrm{m}^{3}$ & 0.05 \\
\hline$V_{4}$ & Vol. between the turbine and the first EB, $\mathrm{m}^{3}$ & 0.002 \\
\hline$V_{5}$ & Volume between the two exhaust brakes, $\mathrm{m}^{3}$ & 0.05 \\
\hline$V_{d}$ & Engine displacement, $\mathrm{m}^{3}$ & 0.003922 \\
\hline & & \\
\hline
\end{tabular}

\section{Conclusion}

The operation of the exhaust brake supported dual loop EGR system modifies the operation of the engine. There are significant changes in the mass flow rates, in the pressures and the turbocharger operation. Therefore, the fuel consumption and the emission of the engine also change. To analyse these effects a pressure-mass flow rate based engine model with five state variables is a suitable opportunity. The state variables are the pressures in the intake and the exhaust manifold, the pressures upstream the two exhaust brakes and the compressor power. The engine model should have four control inputs which are the effective areas of the exhaust gas recirculation valves and the exhaust brakes. The model has two disturbance inputs which are the engine speed and the fuel mass flow rate. Several significant simplifications can be realised. The important ones are the temperatures: on the intake side the temperatures are ambient, on the exhaust side the temperature is the same as in the exhaust manifold which is calculated analytically. The exhaust side temperature is depended on the exhaust gas fraction of the released heat in the cylinders. Also a significant simplification is the handling of the volumetric efficiency and the turbocharger's isentropic efficiencies as a constant. The model parameters can be set to achieve less than $10 \%$ root main square error in transient cycle validation.
1. United Nations Global technical regulation No. 4; 2007.

2. Jiaqiang, E.; Guanlin, L.; Zhiqing, Z.; Dandan, H.; Jingwei, C.; Kexiang, W.; Jinke, G; Zibin, Y. 2019. Effect analysis on cold starting performance enhancement of a diesel engine fueled with biodiesel fuel based on an improved thermodynamic model, Applied Energy 243: 321-335.

3. Chalet, D.; Lesage, M.; Cormerais, M.; Marimbordes, T. 2017. Nodal modelling for advanced thermal-management of internal combustion engine, Applied Energy 90: 99-113.

4. Rajkumar, S.; Thangaraja, J. 2019. Effect of biodiesel, biodiesel binary blends, hydrogenated biodiesel and injection parameters on $\mathrm{NO}_{\mathrm{x}}$ and soot emissions in a turbocharged diesel engine, Fuel 240: 101-118.

5. Zöldy, M. 2019. Investigation of correlation between Diesel fuel cold operability and standardized cold flow properties, Periodica Polytechnica Transportation Engineering.

https://doi.org/10.3311/PPtr.14148.

6. Divekar, D.; Tan, Q.; Chen, X.; Zheng, M. 2015. Characterization of exhaust gas recirculation for diesel low temperature combustion, IFAC-Papers OnLine 4815.

7. Tianpu, D.; Bolan, L.; Fujun, Z.; Yingmin, W.; Baolin, W.; Pan, L. 2017. Control oriented modeling and analysis of gas exchange and combustion processes for LTC diesel engine, Applied Thermal Engineering 110: 1305-1314.

8. Bárdos, Á.; Németh, H. 2011. EGR support investigation on a diesel engine, A Jövő Jármüve 3-4: 48-53.

9. Millo, F.; Giacominetto, P. F.; Bernardi, M. G. 2012. Analysis of different exhaust gas recirculation architectures for passenger car Diesel engines, Applied Energy 98: 79-91.

10. Abián, M.; Martín, C.; Nogueras, P.; Sánchez-Valdepeñas, J.; Rodríguez-Fernández, J.; Lapuerta, M.; Alzueta, U. M. 2018. Interaction of diesel engine soot with $\mathrm{NO}_{2}$ and $\mathrm{O}_{2}$ at diesel exhaust conditions, Effect of fuel and engine operation mode, Fuel 212: 455-461.

11. Luján, J. M.; Climent, H.; Arnau, F. J.; Miguel-García, J. 2018. Analysis of low-pressure exhaust gases recirculation transport and control in transient operation of automotive diesel engines, Applied Thermal Engineering 137: 184-192.

12. Zamboni, G.; Capobianco, M. 2012. Experimental study on the effects of HP and LP EGR in an automotive turbocharged engine, Applied Energy 94: 117-128.

13. Bárdos, A.; Vass, S.; Németh, H. 2014. Validation of a detailed commercial vehicle turbocharged diesel engine model, A Jövő Jármüve 1-2: 25-31. 
14. Isermann, R.; Muller, N. 2003. Design of computer controlled combustion engines, Mechatronics 13: 10671089.

15. Sujesh, G.; Ramesh, S. 2018. Modeling and control of diesel engines: A systematic review, Alexandria Engineering Journal 57: 4033-4048.

16. Kim, S.; Jin, H.; Choi, S. 2014. Pressure and flow based control of a turbocharged Diesel engine air-path system equipped with dual-loop EGR and VGT, American control conference (ACC) Portland, Oregon, USA.

17. Bárdos, Á.; Németh, H. 2013. Control oriented air path model for compressed air boosted Diesel engines, Periodica Polytechnica Transportation Engineering doi: 10.3311/PPtr.7093

18. Jung, H.; Jin, H.; Kim, S.; Choi, S. 2014. Simplified burnt gas fraction estimation for turbocharged Diesel engine with dual loop EGR system, 2014 IEEE Conference on control applications (CCA) Part of 2014 IEEE Multiconference on systems and control Antibes, France

19. Wang, J. 2008. Air fraction estimation for multiple combustion mode diesel engines with dual-loop EGR systems, Control Engineering Practice 16: 1479- 1486.

20. Nielsen, K. V.; Blanke, M.; Eriksson, L.; VejlgaardLaursen, M. 2017. Adaptive feedforward control of exhaust recirculation in large diesel engines, Control Engineering Practice 65: 26-35.

21. Nyerges, Á.; Németh, H. 2016. Control oriented modelling and validation of an exhaust brake supported low pressure exhaust gas recirculation on a medium duty diesel engine, Budapest, VSDIA 2016

22. Bárdos, Á.; Németh, H. 2017. Model development for intake gas composition controller design for commercial vehicle diesel engines with HP EGR and exhaust throttling, Mechatronics 44: 6-13.

23. Reifarth, S. 2014. Efficiency and mixing analysis of EGR-systems for Diesel engines (Doctorate Thesis), Stockholm, TRITA-MMK 2014:01.

24. Sinay, J.; Puškár, M.; Kopas, M. 2018. Reduction of the $\mathrm{NO}_{\mathrm{x}}$ emissions in vehicle diesel engine in order to fulfill future rules concerning emissions released into air, Science of the Total Environment 624: 1421-1428.

25. Hangos, K.; Bokor, J.; Szederkényi ,G. 2004. Analysis and control of nonlinear process systems, Springer, https://doi.org/10.1007/b97665.

26. Guzzella, L.; Onder, C. H. 2010. Introduction to modeling and control of internal combustion engine systems, 2nd ed. Berlin Heidelberg: Springer Verlag. https://doi.org/10.1007/978- 3- 642- 10775- 7.
27. Ammann, M.; Fekete, N.; Guzzella, L.; Glattfelder, A. 2003. Model-based control of the VGT and EGR in a turbocharged common-rail diesel engine: theory and passenger car implementation, SAE Technical Paper 2003-01-0357.

\author{
Á. Nyerges, M. Zöldy \\ MODEL DEVELOPMENT AND EXPERIMENTAL \\ VALIDATION OF AN EXHAUST BRAKE \\ SUPPORTED DUAL LOOP EXHAUST GAS \\ RECIRCULATION ON A MEDIUM DUTY DIESEL \\ ENGINE
}

S u m m a r y

In this paper the modelling process and issues were presented of a turbocharged commercial Diesel engine. The engine is equipped with dual-loop exhaust gas recirculation system which is supported with exhaust brakes. The aim of the paper was to analyse the modelling challenges, discover the simplification possibilities and present a control oriented state-space model. In further researches the dynamic behaviour, the emission and the fuel consumption of the engine will be analysed therefore the given model has to contain these properties. For these aims a pressure-mass flow rate based model type was chosen. The air path system of the engine can be divided into six different balance volumes and finally five state variables were defined. The state variables are pressures in the air path system and the compressor power. The engine has four control inputs which are the effective areas of the exhaust gas recirculation valves and the exhaust brakes. The model has two disturbance inputs which are the engine speed and the fuel mass flow rate. Among the parameters several significant simplifications can be realised. The nonlinear system was also written in state-space form to facilitate control synthesis. The model was validated by engine dyno measurements where a section of World Harmonized Transient Cycle was used. The engine model now is ready for developing an exhaust brake backpressure controller.

Keywords: Diesel engines, Dual loop exhaust gas recirculation, Exhaust brake, Engine model validation.

Received February 04, 2020

Accepted December 01, 2020

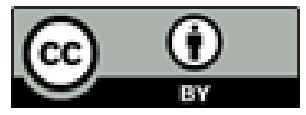

This article is an Open Access article distributed under the terms and conditions of the Creative Commons Attribution 4.0 (CC BY 4.0) License (http://creativecommons.org/licenses/by/4.0/). 